Research Paper

\title{
Portal vein resection and reconstruction with artificial blood vessels is safe and feasible for pancreatic ductal adenocarcinoma patients with portal vein involvement: Chinese center experience
}

\author{
Zhi-Bo Xie ${ }^{1, *}$, Ji-Chun Gu ${ }^{1, *}$, Yi-Fan Zhang ${ }^{2, *}$, Lie Yao ${ }^{1}$, Chen Jin ${ }^{1}$, Yong-Jian Jiang ${ }^{1}$, \\ Ji Li ${ }^{1}$, Feng Yang ${ }^{1}$, Cai-Feng Zou ${ }^{1}$ and De-Liang Fu ${ }^{1}$ \\ ${ }^{1}$ Department of Pancreatic Surgery, Pancreatic Disease Institute, Huashan Hospital, Shanghai Medical College, Fudan \\ University, Shanghai 200040, China \\ ${ }^{2}$ Department of Plastic \& Reconstructive Surgery, Shanghai Ninth People's Hospital, School of Medicine, Shanghai Jiao Tong \\ University, Shanghai 200011, China \\ *These authors have contributed equally to this work \\ Correspondence to: Yi-Fan Zhang, email: dr.yifanzhang@gmail.com \\ De-Liang Fu, email: surgeonfu@163.com \\ Keywords: pancreatic ductal adenocarcinoma, portal vein involvement, pancreaticoduodenectomy, portal vein resection, \\ artificial blood vessels \\ Received: June 13, $2017 \quad$ Accepted: August 17, $2017 \quad$ Published: September 12, 2017 \\ Copyright: Xie et al. This is an open-access article distributed under the terms of the Creative Commons Attribution License 3.0 \\ (CC BY 3.0), which permits unrestricted use, distribution, and reproduction in any medium, provided the original author and source \\ are credited.
}

\section{ABSTRACT}

Evidence shows that portal vein resection (PVR) increase the resectability but does little benefit to overall survival in all pancreatic ductal adenocarcinoma (PDAC) patients. But for patients with portal vein involvement, PVR is the only radical choice. But whether the PDAC patients with portal vein involvement would benefit from radical pancreaticoduodenectomy with PVR or not is controversial. All 204 PDAC patients with portal vein involvement were enrolled in this study [PVR group, $n=106$; surgical bypass (SB) group, $n=52$; chemotherapy group, $n=46]$. Overall survival and prognostic factors were analyzed among three groups. Moreover, a literature review of 13 studies were also conducted. Among 3 groups, patients in PVR group achieved a significant longer survival (median survival: PVR group, 22.83 months; SB group, 7.26 months; chemotherapy group, $\mathbf{1 0 . 6 4}$ months). Therapy choice [hazard ratio $(\mathrm{HR})=1.593,95 \%$ confidence interval $(\mathrm{CI}) 1.323$ to $1.918, P<0.001$ ], body mass index ( $\mathrm{HR}=0.772,95 \% \mathrm{CI} 0.559$ to $0.994, P=0.044)$ and carbohydrateantigen $19-9$ ( $\mathrm{HR}=1.325,95 \% \mathrm{CI} 1.064$ to $1.651, P=0.012)$ were independent prognostic factors which significantly affected overall survival. Pancreaticoduodenectomy combined with PVR and reconstruct with artificial blood vessels is a safe and an appropriate therapy choice for resectable PDAC patients with portal vein involvement.

\section{INTRODUCTION}

Pancreatic ductal adenocarcinoma (PDAC) is one of the most lethal malignant tumors worldwide [1]. The incidence rate of PDAC is increasing in China nowadays [2]. PDAC is a devastating malignant disease and associated with a rather poor prognosis. Median survival of PDAC patients is 3 to 6 months and 5-year survival rate is less than $6 \%[3-6]$.
For PDAC patients, pancreatic surgery currently provides the only chance of cure or long-term survival [7]. However, most patients are not candidates for surgical resection due to distant metastasis or vascular involvement at the time of diagnosis [8]. Vascular involvement used to be a contradiction for PDAC surgery because patients with vascular involvement have a high risk of systemic metastasis possibility [9]. With improvements in surgical technique, anesthesia, and critical care support, there has been renewed 
interest in vascular resection for isolated involvement of the portal vein (PV) in resectable PDAC [10]. PV resection (PVR) has been proved to be safe, however, the use of PVR is still debatable. Many studies claim that PVR increase the resectability of PDAC, but do little benefit to survival [11-13]. Nevertheless, a newly published meta-analysis find out that pancreatic resection with PVR are associated with increased postoperative mortality, higher rates of non-radical surgery and worse survival [14].

Interestingly, we find there is no exact guideline therapy for PDAC patients with PV involvement. According to TNM classification, PV involvement was classified as $\mathrm{T}_{3}$ (tumor stage II). Almost all studies enrolled $\mathrm{T}_{3}$ adenocarcinoma patients for PVR, while there were still some studies enrolled $\mathrm{T}_{1-2}$ and $\mathrm{T}_{4}[15,16]$, even with $\mathrm{M}_{1}$ adenocarcinoma patients as the candidates for PVR $[11,17]$. As for the patients without PVR, tumor stage vary from I to IV [11, 18-22]. Based on such incomparable baseline characteristics, we could not find out the appropriate therapy for patients with PV involvement.

Patients with PV involvement are associated with a late tumor stage and a worse prognosis compared with patients without PV involvement. The difference among the chosen study population may conclude an improper result. For PDAC patients with PV involvement, the only choice for cure is pancreatic surgery with PVR when the tumor is resectable. With regard to PDAC patients with unresectable tumors, chemotherapy may be a good choice, and surgical bypass (SB) may be another choice to improve life quality when obstructive symptoms occurs. Thus which therapy will get the most benefit for PDAC patients with PV involvement still needs further consideration.

Moreover, venous end to end anastomosis is the most usual reconstruction method during PVR procedures $[7,11,20,21]$. Remaining tumor cells on the venous stump may help to produce distal metastasis. Artificial blood vessels, are composed of viable tissue represent the ideal vascular graft. Compared with self-venous, compliance, lack of thrombogenicity, and resistance to infections as well as the ability to heal, remodel, contract, and secrete normal blood vessel products are theoretical advantages of artificial blood vessels [23, 24]. With the artificial blood vessels, tumor cell would not be easy to adhere, penetrate and develop distal metastasis.

Based on above concerns, we enrolled all PDAC patients with PV involvement. Performing PVR and using artificial blood vessels for venous reconstruct. We aim to find out whether PVR and reconstruct with artificial blood vessels would benefit for these PDAC patients and to search and provide a proper therapy for PDAC patients with PV involvement.

\section{RESULTS}

\section{Characteristics of the study population}

From 2010 to 2015, 1382 potential eligible PDAC patients were enrolled in this study. Altogether 209 PDAC patients were found to satisfy the inclusion and exclusion criteria (PVR group, $\mathrm{n}=111$; SB group, $\mathrm{n}=50$; chemo group, $\mathrm{n}=46$ ). However, three PDAC patients in PVR group were found liver metastasis during intraoperative exploration. They underwent SB procedure and were excluded from our study. Another two PDAC patients in PVR group were found that primary tumors were without the ability of reconstruction, and underwent SB procedure thus were divided into SB group. Finally 204 eligible PDCA patients were divided into PVR group $(n=106)$, SB group $(n=52)$ and chemo group $(n=46)$. At baseline, compared with the patients in PVR and SB group, patients in chemo group are more likely to have lower serum ALB levels and a significantly higher serum level of carbohydrateantigen (CA) 19-9 and CA 50 (Table 1).

\section{Overall survival and related risk factors}

In our study, median survivals for patients with PVR, SB and chemotherapy were 22.83 months, 7.26 months and 10.64 months respectively. Among which, patients with PVR had a significantly longer survival (PVR vs. SB, $P<0.001$; PVR vs. Chemo, $P<0.001$ ). Patients in chemotherapy group seemed to have better survivals than patients in SB group, but the difference was not significant $(P=0.064)$. Univariate and multivariate regression analysis found therapy choice [hazard ratio $(\mathrm{HR})=1.593,95 \%$ confidence interval $(\mathrm{CI}) 1.323$ to 1.918 , $P<0.001]$, body mass index (BMI) $(\mathrm{HR}=0.772,95 \% \mathrm{CI}$ 0.559 to $0.994, P=0.044)$ and $\mathrm{CA} 19-9(\mathrm{HR}=1.325,95 \%$ CI 1.064 to $1.651, P=0.012$ ) could significantly affect overall survival (OS) (Figure 1, Table 2).

After performing the survival analysis among all PDAC patients, we then conducted univariate and multivariate regression analysis in patients with PVR in order to find out prognostic factors related with OS in patients with radical therapy. We found pathological PV involvement $(\mathrm{HR}=3.038,95 \%$ CI 1.161 to 7.948 , $P=0.024)$, BMI $(\mathrm{HR}=0.582,95 \%$ CI 0.374 to 0.904 , $P=0.016)$, CA $19-9$ (HR=1.686, 95\% CI 1.099 to 2.586 , $P=0.017)$ and lymph node metastasis $(\mathrm{HR}=2.541,95 \%$ CI 1.455 to $4.438, P=0.001$ ) were independent prognostic factors which significantly affected OS. Survival analysis were then performed with these risk factors and found patients with pathological PV involvement, worse BMI, higher CA 19-9 levels and lymph node metastasis achieved significantly worse survivals (Figure 2, Table 3).

\section{Surgery and Surgical complications}

Together 158 patients underwent surgical procedure, 106 patients underwent PD with synchronous PVR and another 52 underwent SB. Compared with patients in SB group, patients in PVR group suffered significantly longer operation time (478.14 mins vs. $213.50 \mathrm{mins}, P<0.001$ ), more blood loss (600 ml vs. $120 \mathrm{ml}, P<0.001)$, and longer hospital stay (21.02 days vs. 12.37 days, $P<0.001)$. In 
Table 1: Baseline characteristics of the enrolled patients

\begin{tabular}{|c|c|c|c|c|}
\hline Index & PVR Group $(n=106)$ & SB Group $(n=52)$ & Chemo Group $(n=46)$ & P value \\
\hline Male, n (\%) & $65,61.3 \%$ & $35,67.3 \%$ & $28,60.9 \%$ & 0.732 \\
\hline Age, years & $61.45 \pm 9.19$ & $61.87 \pm 10.62$ & $60.30 \pm 18.31$ & 0.804 \\
\hline Body mass index, $\mathrm{kg} / \mathrm{m}^{2}$ & $22.26 \pm 2.79$ & $21.68 \pm 2.81$ & $21.92 \pm 3.65$ & 0.511 \\
\hline Diabetes, n (\%) & $19,17.9 \%$ & $6,11.5 \%$ & $5,10.9 \%$ & 0.400 \\
\hline Leukocyte, $10^{9} / \mathrm{L}$ & $5.65 \pm 1.71$ & $5.71 \pm 1.83$ & $6.15 \pm 2.52$ & 0.334 \\
\hline Albumin, $g / \mathrm{L}$ & $40.10 \pm 3.71$ & $38.81 \pm 4.79$ & $36.93 \pm 5.14$ & $<0.001$ \\
\hline Total bilirubin, $\mu \mathrm{mol} / \mathrm{L}$ & $12.21(11.00-32.73)$ & $12.00(9.93-23.63)$ & $6.60(5.28-12.03)$ & 0.218 \\
\hline $\begin{array}{l}\text { Alanine Transaminase, } \\
\mathrm{U} / \mathrm{L}\end{array}$ & $37.50(18.00-101.00)$ & $33.50(14.25-67.75)$ & $29.00(15.00-49.25)$ & 0.054 \\
\hline $\mathrm{CEA}, \mu \mathrm{g} / \mathrm{L}$ & $3.34(1.97-6.95)$ & $3.29(2.10-8.75)$ & $3.00(2.08-4.66)$ & 0.383 \\
\hline $\mathrm{CA} 125, \mathrm{U} / \mathrm{ml}$ & $42.27(25.51-78.92)$ & $40.04(26.06-52.00)$ & $39.00(21.63-52.00)$ & 0.127 \\
\hline CA 19-9, U/ml & $\begin{array}{c}116.25(36.00- \\
375.480)\end{array}$ & $\begin{array}{c}380.55(49.88- \\
816.30)\end{array}$ & $\begin{array}{c}441.50(96.25- \\
683.50)\end{array}$ & $<0.001$ \\
\hline CA $50, \mathrm{U} / \mathrm{ml}$ & $34.50(10.63-73.20)$ & $34.50(23.00-71.25)$ & $62.25(25.00-170.98)$ & $<0.001$ \\
\hline Tumor diameters, $\mathrm{cm}$ & $4.00 \pm 1.31$ & $5.56 \pm 2.10$ & / & 0.304 \\
\hline \multicolumn{5}{|l|}{ Tumor stage } \\
\hline Stage IIA, n (\%) & $51,48.0 \%$ & / & / & / \\
\hline Stage IIB, n (\%) & $55,52.0 \%$ & l & / & / \\
\hline Time, minutes & $478.14 \pm 93.78$ & $213.50 \pm 89.73$ & / & $<0.001$ \\
\hline Blood loss, ml & $\begin{array}{c}600.00(487.50- \\
544.25)\end{array}$ & $\begin{array}{c}120.00(75.00- \\
240.00)\end{array}$ & / & $<0.001$ \\
\hline R1 resection, $\%$ & $5,4.7 \%$ & l & / & l \\
\hline Hospital stay, days & $21.02 \pm 8.78$ & $12.37 \pm 2.62$ & $9.78 \pm 3.73$ & $<0.001$ \\
\hline
\end{tabular}

Abbreviation: $\mathrm{CA}=$ Carbohydrateantigen, $\mathrm{CEA}=$ Carcinoembryonic antigen, $\mathrm{PVR}=$ Portal vein resection, $\mathrm{SB}=$ surgical bypass.

patients underwent pancreaticoduodenectomy (PD) combined with PVR, 4.7\% (5/106) of patients were found $\mathrm{R} 1$ resection. Moreover, pathological evidence from 10 patients $(9.4 \%)$ in PVR group were found without $\mathrm{PV}$ involvement while other patients were all with pathological PV involvement.

No operation related death occurred and no inhospital death were observed. During the hospital stay, no serious complications which threaten life or needing secondary operation occurred. Patients in PVR group suffered significantly higher incidence of pancreatic fistula, pleural effusion (Table 4). The difference of other complications between patients in PVR group and SB group were similar which showed PD combined with PVR was safe. B-ultrasonic test and computed tomography (CT) was required at every reexamination within postoperative 3 month to determine the condition of the interposition graft. Within postoperative 3 months, no graft infection and thrombosis was reported in patients in PVR group. Only 2 patients were observed postoperative bleeding during the hospital-stay.

\section{Literature review}

Together 13 studies from 8 countries satisfied our include criteria $[11,15,17,18,20,21,25-31]$. In these 13 studies, study sample varied from 78 patients to 1070 patients. We found there were 2 studies [25, 30] only enrolled stage II PDAC patients, however, enrolled patients in other studies varied from stage I to IV. Sample size of patients with PVR in 5 studies [11, 15, 16, 28, 30] was more than 100 , while other studies were with a small sample size. Together 6 studies [11, 18, 21, 25-27] used both self-anastomosis (end to end anastomosis, suture, patch, autograft) and prosthesis (allograft), and other 6 studies [15, 17, 28-31] used self-anastomosis (Table 5). 
In survival analysis, we found 7 studies $[11,15-17$, 28, 29, 31] showed patients with PVR suffered from a worse OS than patients without PVR. However, rest 6 studies found the survival was similar between patients with or without PVR [18, 21, 25-27, 30]. A recently published meta-analysis [14] also showed one-, 3- and 5-year survival were worse in the PV- superior mesenteric vein (SMV) resection group. However, median overall survival was similar between 2 groups (14.3 months vs. 19.5 months, $P$ $=0.063)$.

\section{DISCUSSION}

For PDAC patients, pancreatic surgery provides the only chance for cure. However, only $20 \%$ of PDAC patients are eligible for surgery [32]. PV involvement used to be the contradictions for pancreatic surgery. At present, patients with PV involvement already have got the chance to be cured since the great improvement of the techniques and perioperative management. Currently, almost all studies are focusing on the benefits of PVR and few studies focused on how to choose the appropriate treatment for patients with PV involvement. At present, studies enrolled patients in all tumor stage, and pay little attention on patients with PV involvement. Those studies found out that PD combined with PVR only provided more chance for resection but did little to OS. Thus, we conducted the present study and patients we enrolled were all with PV involvement to solve such controversial issues. In the present study, we found out that patients received PD combined with PVR achieved a better OS compared with patients with SB and chemotherapy. PD combined with PVR is a safe and feasible therapy for patients with PV involvement.

Lots of studies [11, 28, 29] and newly published meta-analysis [14] claimed that patients with PVR had significantly worse survival. However, we found patients with PVR achieved the longest OS (mean survival: PVR, 22.83 months; SB, 7.26 months; Chemo, 10.64 months). This difference may due largely to the characeristics of enrolled populations. We only enrolled PDAC patients with PV involvement in this study in order to find out an
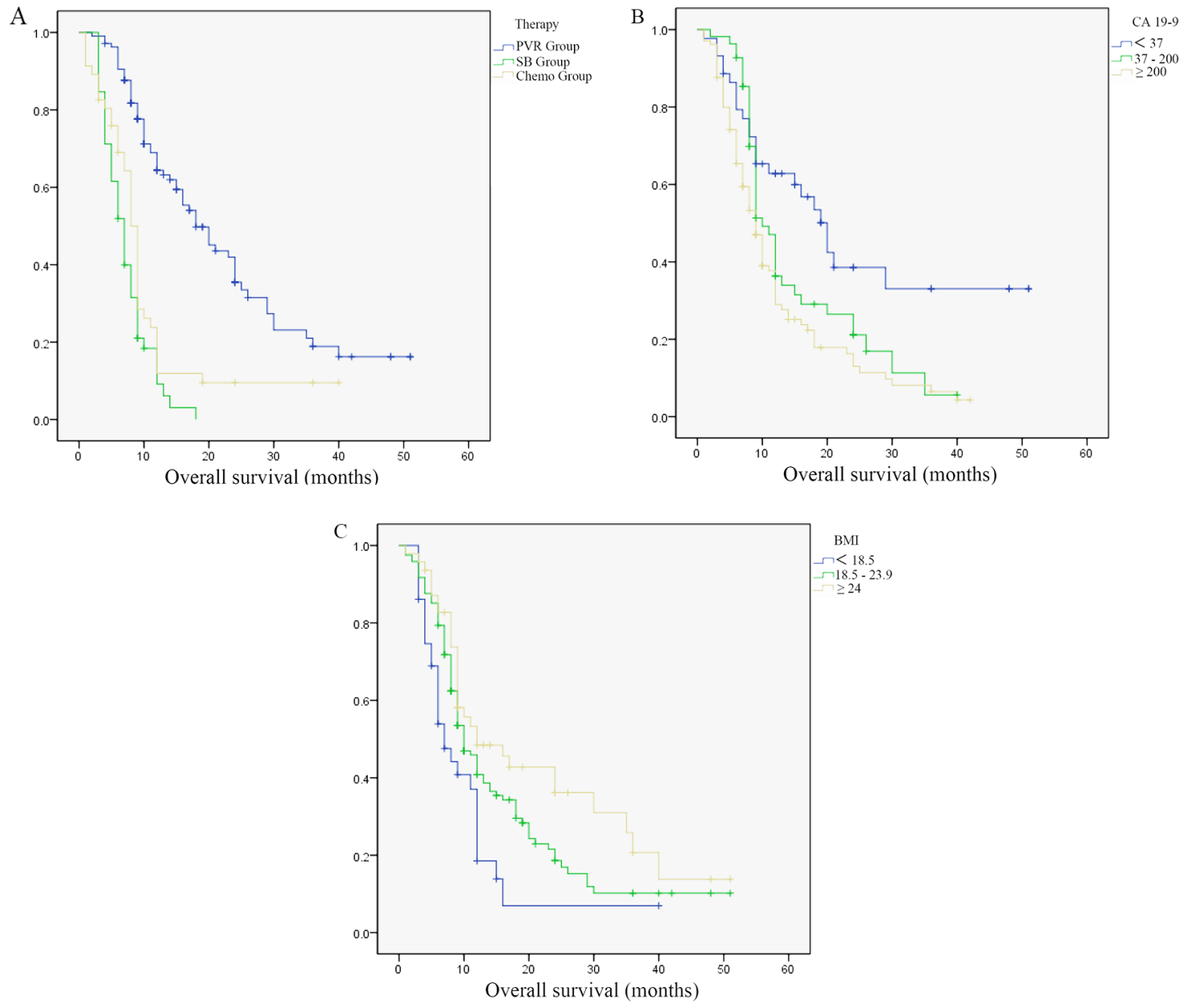

Figure 1: Survivals difference in all pancreatic ductal adenocarcinoma patients. (A) Survivals difference in patients with different therapy. (B) Survivals difference in patients with different carbohydrateantigen 19-9 levels. (C) Survivals difference in patients with different body mass index. 
Table 2: Multivariate analysis of risk factors related with overall survivals in all patients

\begin{tabular}{|c|c|c|c|c|c|c|c|c|}
\hline \multirow[t]{2}{*}{ Risk factors } & \multicolumn{3}{|c|}{ Univariate analysis } & \multicolumn{3}{|c|}{ Multivariate analysis } & \multicolumn{2}{|c|}{ Overall survival } \\
\hline & HR & $95 \%$ CI & $P$ value & HR & $95 \% \mathrm{CI}$ & $P$ value & $\begin{array}{c}\text { Mean } \pm S D \\
\text { months }\end{array}$ & P value \\
\hline \multicolumn{9}{|l|}{ Therapy } \\
\hline Group 1: PVR & 1.711 & $1.427-2.050$ & $<0.001$ & 1.593 & $1.323-1.918$ & $<0.001$ & $22.826 \pm 1.762$ & $\begin{array}{l}1 \text { vs. } 2:<0.001 ; \\
2 \text { vs. } 3: 0.064 ; \\
1 \text { vs. } 3:<0.001\end{array}$ \\
\hline Group 2: SB & & & & & & & $7.261 \pm 0.530$ & \\
\hline Group 3: Chemo & & & & & & & $10.643 \pm 1.556$ & \\
\hline \multicolumn{9}{|l|}{ Body mass index } \\
\hline Group 1: $<18.5$ & 0.662 & $0.508-0.863$ & 0.002 & 0.772 & $0.599-0.994$ & 0.044 & $10.302 \pm 1.863$ & $\begin{array}{l}1 \text { vs. } 2: 0.015 \\
2 \text { vs. } 3: 0.079 ; \\
1 \text { vs. } 3: 0.003\end{array}$ \\
\hline Group 2: 18.5-23.9 & & & & & & & $15.940 \pm 1.441$ & \\
\hline Group 3: $>24$ & & & & & & & $21.493 \pm 2.687$ & \\
\hline \multicolumn{9}{|l|}{ CA $19-9$} \\
\hline Group 1: <37 & 1.498 & $1.211-1.852$ & $<0.001$ & 1.325 & $1.064-1.651$ & 0.012 & $25.287 \pm 3.294$ & $\begin{array}{l}1 \text { vs. } 2: 0.042 \\
2 \text { vs. } 3: 0.072 \\
1 \text { vs. } 3:<0.001\end{array}$ \\
\hline Group 2: 37-200 & & & & & & & $15.387 \pm 1.570$ & \\
\hline Group 3: >200 & & & & & & & $12.471 \pm 1.142$ & \\
\hline \multicolumn{9}{|l|}{ Gender } \\
\hline Group 1:Male & 0.907 & $0.653-1.260$ & 0.562 & - & - & - & - & - \\
\hline Group 2:Female & & & & & & & & \\
\hline \multicolumn{9}{|l|}{ Age } \\
\hline Group 1:<65 & 1.133 & $0.813-1.581$ & 0.460 & - & - & - & - & - \\
\hline \multicolumn{9}{|l|}{ Group 2: $\geq 65$} \\
\hline \multicolumn{9}{|l|}{ Albumin } \\
\hline Group 1: $<35$ & 0.676 & $0.452-1.010$ & 0.056 & - & - & - & - & - \\
\hline \multicolumn{9}{|l|}{ Group 2: $\geq 35$} \\
\hline \multicolumn{9}{|l|}{ Total bilirubin } \\
\hline Group 1: <12 & 0.941 & $0.681-1.300$ & 0.713 & - & - & - & - & - \\
\hline \multicolumn{9}{|l|}{ Group $2: \geq 12$} \\
\hline \multicolumn{9}{|l|}{ Alanine Transaminase } \\
\hline Group 1: <80 & 1.063 & $0.728-1.553$ & 0.753 & - & - & - & - & - \\
\hline \multicolumn{9}{|l|}{ Group $2: \geq 80$} \\
\hline \multicolumn{9}{|l|}{$\begin{array}{l}\text { Carcinoembryonic } \\
\text { antigen }\end{array}$} \\
\hline Group 1: <5 & 0.915 & $0.645-1.229$ & 0.620 & - & - & - & - & - \\
\hline \multicolumn{9}{|l|}{ Group $2: \geq 5$} \\
\hline \multicolumn{9}{|l|}{ CA 125} \\
\hline Group 1: <35 & 1.365 & $0.998-1.886$ & 0.059 & - & - & - & - & - \\
\hline \multicolumn{9}{|l|}{ Group 2: $\geq 35$} \\
\hline \multicolumn{9}{|l|}{ CA 50} \\
\hline Group 1: <24 & 0.384 & 0.999-1.002 & 0.384 & - & - & - & - & - \\
\hline Group $2: \geq 24$ & & & & & & & & \\
\hline
\end{tabular}

Abbreviation: $\mathrm{CA}=$ Carbohydrateantigen, $\mathrm{CI}=$ Confidence interval, $\mathrm{HR}=$ Hazard ratio, $\mathrm{PVR}=$ Portal vein resection, $\mathrm{SB}=$ surgical bypass. 
Table 3: Multivariate analysis of risk factors related with overall survivals in patients with PVR

\begin{tabular}{|c|c|c|c|c|c|}
\hline \multirow[t]{2}{*}{ Risk factors } & \multicolumn{3}{|c|}{ Multivariate analysis } & \multicolumn{2}{|c|}{ Overall survival } \\
\hline & HR & $95 \%$ CI & P value & Mean \pm SD, months & P value \\
\hline \multicolumn{6}{|l|}{ Pathological PV invasion } \\
\hline Group 1: Yes & 3.038 & $1.161-7.948$ & 0.024 & $21.485 \pm 1.874$ & 0.037 \\
\hline Group 2: No & & & & $35.143 \pm 4.028$ & \\
\hline \multicolumn{6}{|l|}{ Body mass index } \\
\hline Group 1: $<18.5$ & 0.582 & $0.374-0.904$ & 0.016 & $11.594 \pm 1.157$ & $\begin{array}{l}1 \text { vs. } 2: 0.043 \\
2 \text { vs. } 3: 0.039 \\
1 \text { vs. } 3:<0.001\end{array}$ \\
\hline Group 2: $18.5-23.9$ & & & & $21.481 \pm 2.137$ & \\
\hline Group 3: > 24 & & & & $30.481 \pm 3.480$ & \\
\hline \multicolumn{6}{|l|}{ CA 19-9 } \\
\hline Group 1: <37 & 1.686 & $1.099-2.586$ & 0.017 & $32.353 \pm 3.863$ & $\begin{array}{l}1 \text { vs. } 2: 0.028 ; \\
2 \text { vs. } 3: 0.531 ; \\
1 \text { vs. 3: } 0.002\end{array}$ \\
\hline Group 2: $37-200$ & & & & $19.619 \pm 2.294$ & \\
\hline Group 3: >200 & & & & $17.747 \pm 1.837$ & \\
\hline \multicolumn{6}{|l|}{ Lymph node metastasis } \\
\hline Group 1: Yes & 2.541 & $1.455-4.438$ & 0.001 & $15.117 \pm 1.167$ & $<0.001$ \\
\hline Group 2: No & & & & $29.077 \pm 2.639$ & \\
\hline
\end{tabular}

Abbreviation: $\mathrm{CA}=$ Carbohydrateantigen, $\mathrm{CI}=$ Confidence interval, $\mathrm{HR}=$ Hazard ratio, $\mathrm{PV}=$ Portal vein, $\mathrm{PVR}=$ Portal vein resection.
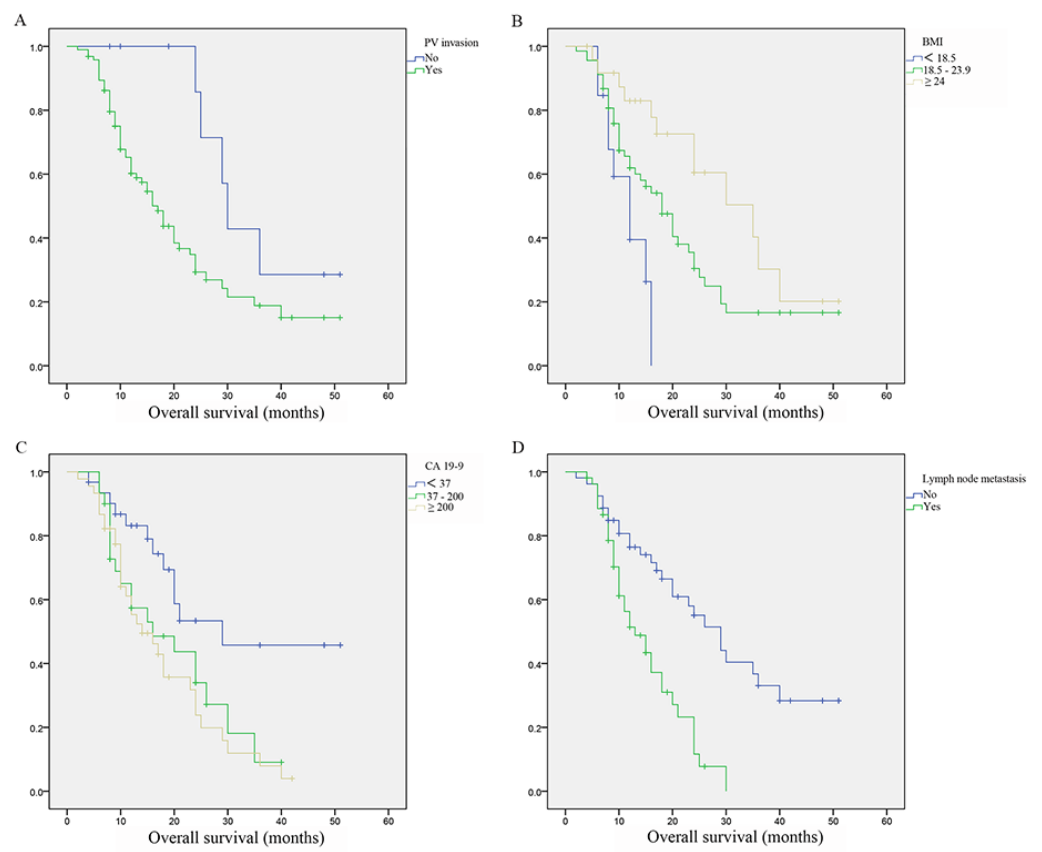

Figure 2: Survivals difference in pancreatic ductal adenocarcinoma patients with portal vein resection. (A) Survivals difference in patients with or without portal vein invasion. (B) Survivals difference in patients with different body mass index. (C) Survivals difference in patients with different carbohydrateantigen 19-9 levels. (D) Survivals difference in patients with or without lymph node metastasis. 
Table 4: Postoperative complications in patients with portal vein resection or surgical bypass

\begin{tabular}{lccc}
\hline Postoperative complications & PVR Group (n=106) & SB Group (n=52) & P value \\
\hline Pancreatic fistula (A/B/C), n (\%) & $32(30.2 \%) / 16(15.1 \%) / 0(0.0 \%)$ & $1(1.9 \%) / 0(0.0 \%) / 0(0.0 \%)$ & $<0.001$ \\
Delayed gastric empting, n (\%) & $6(5.7 \%)$ & $0(0.0 \%)$ & 0.179 \\
Postoperative bleeding, n (\%) & $2(1.9 \%)$ & $0(0.0 \%)$ & $>0.999$ \\
Wound infection, n (\%) & $8(7.5 \%)$ & $2(3.8 \%)$ & 0.499 \\
Pleural effusion, n (\%) & $17(16.0 \%)$ & $2(3.8 \%)$ & 0.035 \\
Abdominal infection, n (\%) & $2(1.9 \%)$ & $0(0.0 \%)$ & $>0.999$ \\
\hline
\end{tabular}

Abbreviation: $\mathrm{PVR}=$ Portal vein resection, $\mathrm{SB}=$ surgical bypass.

Table 5: A systematic review of published studies

\begin{tabular}{|c|c|c|c|c|c|c|c|c|}
\hline Study & Year & Country & PVR & Patients, $n$ & Anastomosis & $\begin{array}{c}\text { Tumor stage: } 0 / \mathbf{I} / \mathrm{II} / \\
\text { III/IV }\end{array}$ & Survival & Risk factors related with OS \\
\hline \multirow[t]{2}{*}{ Bachellier et al. } & 2001 & France & Yes & 21 & $\mathrm{~S}, \mathrm{P}$ & $0 / 0 / 5 / 4 / 12$ & $\begin{array}{c}\text { 1-year survival: } 53.6 \% \text {; } \\
\text { 2-year survival:21.5\% }\end{array}$ & N/A \\
\hline & & & No & 66 & N/A & $1 / 7 / 12 / 30 / 16$ & $\begin{array}{l}\text { 1-year survival: } 51.1 \% \text {; } \\
\text { 2-year survival: } 24.3 \%\end{array}$ & \\
\hline \multirow[t]{2}{*}{ Chakravarty et al. } & 2010 & China & Yes & 12 & $\mathrm{~S}, \mathrm{P}$ & $0 / 0 / 12 / 0 / 0$ & $\begin{array}{c}\text { 1-year survival: } 50.0 \% \\
\text { 3-year survival: } 16.7 \%\end{array}$ & $\begin{array}{c}\text { Bilirubin, tumor } \\
\text { differentiation, and adjuvant } \\
\text { chemotherapy }\end{array}$ \\
\hline & & & No & 75 & $\mathrm{~N} / \mathrm{A}$ & $0 / 0 / 75 / 0 / 0$ & $\begin{array}{c}\text { 1-year survival: } 44.4 \% \\
\text { 3-year survival:12.2\% }\end{array}$ & \\
\hline \multirow[t]{2}{*}{ Cheung et al. } & 2004 & China & Yes & 32 & $\mathrm{~S}, \mathrm{P}$ & $0 / 5 / 26 / 1 / 0$ & $\begin{array}{l}\text { 1-year survival: } 70.6 \% \text {; } \\
\text { 3-year survival: } 22.2 \%\end{array}$ & Disease stage \\
\hline & & & No & 46 & N/A & $0 / 6 / 39 / 1 / 0$ & $\begin{array}{l}\text { 1-year survival: } 71.1 \% \text {; } \\
\text { 3-year survival: } 13.5 \%\end{array}$ & \\
\hline \multirow[t]{2}{*}{ Fils et al. } & 2016 & Slovenia & Yes & 22 & $\mathrm{~S}, \mathrm{P}$ & $\mathrm{T}_{3}: 22$ & Median OS: 16.2 mons & $\mathrm{N} / \mathrm{A}$ \\
\hline & & & No & 111 & N/A & $\mathrm{T}_{1}: 10, \mathrm{~T}_{2}: 26, \mathrm{~T}_{3}: 75$ & Median OS: 15.1 mons & \\
\hline \multirow[t]{2}{*}{ Gong et al. } & 2013 & China & Yes & 119 & $\mathrm{~S}, \mathrm{P}$ & $0 / 4 / 78 / 35 / 2$ & $\begin{array}{c}\text { 1-year survival: } 30.0 \% \text {; } \\
\text { 3-year survival: } 8.1 \%\end{array}$ & $\begin{array}{l}\text { The degree of tumor } \\
\text { differentiation and the } \\
\text { occurrence of complications } \\
\text { after surgery }\end{array}$ \\
\hline & & & No & 447 & N/A & $0 / 36 / 84 / 3 / 0$ & $\begin{array}{l}\text { 1-year survival: } 55.1 \% \text {; } \\
\text { 3-year survival: } 21.2 \%\end{array}$ & \\
\hline \multirow[t]{2}{*}{ Hartel et al. } & 2002 & Germany & Yes & 68 & $\mathrm{~S}, \mathrm{P}$ & $0 / 0 / 6 / 6 / 56$ & 5 -year survival: $23 \%$ & N/A \\
\hline & & & No & 203 & N/A & $0 / 27 / 50 / 124 / 2$ & 5 -year survival: $24 \%$ & \\
\hline \multirow[t]{2}{*}{ Hwang et al. } & 2015 & Korea & Yes & 147 & $\mathrm{~S}$ & $\begin{array}{c}\mathrm{T}_{1}: 4, \mathrm{~T}_{2}: 9, \mathrm{~T}_{3}: 363, \\
\mathrm{~T}_{4}: 20\end{array}$ & Median OS: 17.2 mons & $\begin{array}{l}\text { The extent of venous } \\
\text { involvement, LNM, and } \\
\text { adjuvant chemotherapy }\end{array}$ \\
\hline & & & No & 396 & N/A & $\mathrm{T}_{1}: 2, \mathrm{~T}_{2}: 3, \mathrm{~T}_{3}: 136, \mathrm{~T}_{4}: 6$ & Median OS: 21.0 mons & \\
\hline \multirow[t]{2}{*}{ Mierke et al. } & 2016 & Germany & Yes & 113 & N/A & $\mathrm{T}_{1}+\mathrm{T}_{2}: 4, \mathrm{~T}_{3}+\mathrm{T}_{4}: 109$ & $\begin{array}{c}\text { Median DFS: } \mathrm{P}^{+} \mathrm{I}^{+}, 7.4 \text { mons; } \\
\mathrm{P}^{+} \mathrm{I}^{-}, 10.9 \text { mons }\end{array}$ & True PV/SMV invasion \\
\hline & & & No & 66 & N/A & $\mathrm{T}_{3}+\mathrm{T}_{4}: 66$ & Median DFS: 11.6 & \\
\hline \multirow[t]{2}{*}{ Murakami et al. } & 2013 & Japan & Yes & 61 & $\mathrm{~S}$ & $\mathrm{~T}_{1}+\mathrm{T}_{2}: 1, \mathrm{~T}_{3}: 61$ & Median OS: 14.7 mons & Adjuvant chemotherapy \\
\hline & & & No & 64 & N/A & $\mathrm{T}_{1}+\mathrm{T}_{2}: 7, \mathrm{~T}_{3}: 57$ & Median OS: 26.7 mons & \\
\hline \multirow[t]{2}{*}{ Murakami et al. } & 2015 & Japan & Yes & 435 & $\mathrm{~S}$ & $\mathrm{~T}_{1}+\mathrm{T}_{2}: 13, \mathrm{~T}_{3}+\mathrm{T}_{4}: 422$ & Median OS: 18.5 mons & $\begin{array}{l}\text { Preoperative resectability } \\
\text { status, CA19-9, blood } \\
\text { transfusion, postoperative } \\
\text { complications, LNM, and } \\
\text { tumor stage }\end{array}$ \\
\hline & & & No & 502 & N/A & $\mathrm{T}_{1}+\mathrm{T}_{2}: 69, \mathrm{~T}_{3}+\mathrm{T}_{4}: 433$ & Median OS: 25.8 mons & \\
\hline
\end{tabular}




\begin{tabular}{|c|c|c|c|c|c|c|c|c|}
\hline Study & Year & Country & PVR & Patients, $\mathbf{n}$ & Anastomosis & $\begin{array}{c}\text { Tumor stage: } 0 / \mathbf{I} / \mathbf{I I} / \\
\text { III/IV }\end{array}$ & Survival & Risk factors related with OS \\
\hline \multirow[t]{2}{*}{ Ouaissi et al. } & 2010 & Belgium & Yes & 59 & $\mathrm{~S}$ & $0 / 20 / 58 / 0 / 4$ & Median OS: 17.5 mons & $\begin{array}{l}\text { CA19-9, combined venous } \\
\text { resection, and LNM }\end{array}$ \\
\hline & & & No & 82 & N/A & $0 / 10 / 37 / 11 / 1$ & Median OS: 18.7 mons & \\
\hline \multirow[t]{2}{*}{ Ravikumar et al. } & 2014 & England & Yes & 230 & $\mathrm{~S}$ & $0 / 0 / 230 / 0 / 0$ & Median OS: 18.2 mons & N/A \\
\hline & & & No & 840 & N/A & $0 / 0 / 840 / 0 / 0$ & Median OS: 18.0 mons & \\
\hline \multirow[t]{2}{*}{ Shimada et al. } & 2006 & Japan & Yes & 86 & $\mathrm{~S}$ & $0 / 0 / 47 / 0 / 39$ & Median OS: 14 mons & $\begin{array}{l}\text { CA19-9, tumor size, serosal } \\
\text { invasion, duodenal invasion, } \\
\text { PV invasion, extra-pancreatic } \\
\text { nerve plexus invasion, LNM, } \\
\text { PVR, cancer infiltration } \\
\text { at surgical margins, and } \\
\text { intraoperative radiation therapy }\end{array}$ \\
\hline & & & No & 53 & $\mathrm{~N} / \mathrm{A}$ & $0 / 2 / 46 / 0 / 5$ & Median OS: 35 mons & \\
\hline
\end{tabular}

Abbreviation: $\mathrm{CA}=$ carbohydrate antigen; $\mathrm{DFS}=$ disease free survival; $\mathrm{LNM}=$ lymph node metastasis; $\mathrm{N} / \mathrm{A}=$ not available; $\mathrm{OS}=\mathrm{overall}$ survival; $\mathrm{P}^{+} \mathrm{I}^{+}=\mathrm{PV}$ resection and with $\mathrm{PV}$ infiltration; $\mathrm{P}^{+} \mathrm{I}=\mathrm{PV}$ resection and without $\mathrm{PV}$ infiltration; $\mathrm{PVR}=$ portal vein resection; $\mathrm{P}=$ prosthesis (allograft); $\mathrm{S}=$ self-anastomosis (end to end anastomosis, suture, patch, autograft); SMV=superior mesenteric vein.

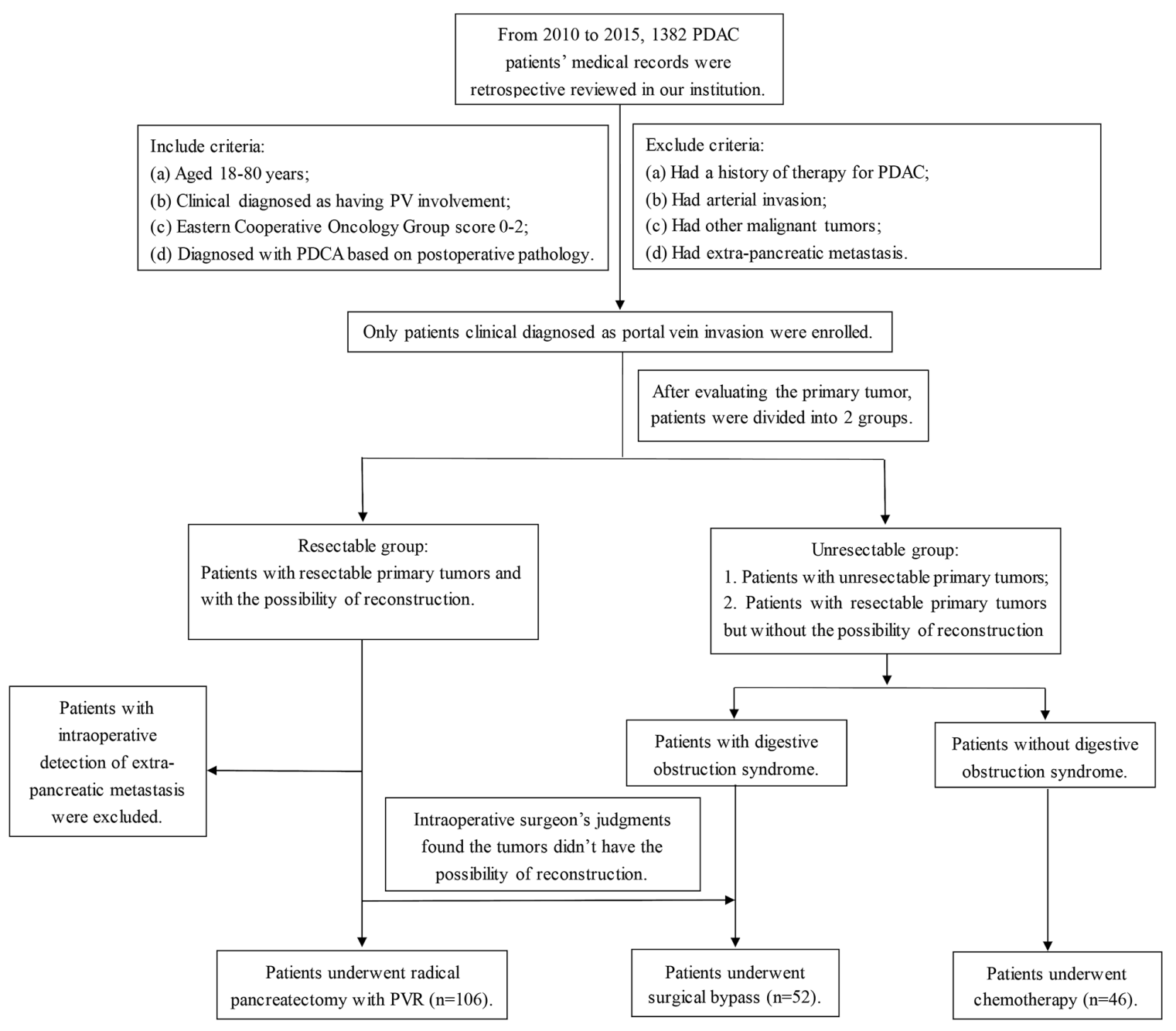

Figure 3: Selection flow. Notes: From 2010 to 2015, 1382 potential eligible PDAC patients were enrolled in this study. Altogether 209 patients satisfied the inclusion and exclusion criteria (PVR group, $\mathrm{n}=111$; SB group, $\mathrm{n}=50$; chemo group, $\mathrm{n}=46$ ). Three patients in PVR group were found liver metastasis during intraoperative exploration and were excluded. Tumors of two patients in PVR group were without the ability of reconstruction, thus undergoing SB procedure and were divided into SB group. Finally 204 eligible PDCA patients were enrolled (PVR group, n=106; SB group, n=52; chemo group, n=46). 
appropriate therapy for them. In Shimada et al.'s study [31], patients underwent PVR had significantly worse OS than patients without (median survival: 14 months vs. 35 months). In their PVR group, 45.3\% (39/86) of patients were with extra-pancreatic metastasis (tumor stage IV), however, there were only $9.4 \%$ of patients in non-PVR group were tumor stage IV. Based on such incomparable baseline characteristics, it is no wonder that patients in PVR group suffered significantly worse OS. In Ravikumar et al.'s study [30], they only enrolled stage II PDAC patients and found median survival was 18 months for patients with PD, 18.2 months for patients with PD combined with PVR, and 8 months for patients with SB. Compared with our findings (mean survival: PVR, 22.83 months; SB, 7.26 months; Chemo, 10.64 months), the result was similar. According to TNM classification stage, PV involvement and peri-pancreatic involvement were both classified as stage II. In patients with peri-pancreatic involvement PVR in no more needed, thus, they could set a group which only needed PD. However, in patients with PV involvement, PVR was the only choice for radical resection. That is why we only have 3 groups (PVR group, SB group and chemotherapy group) in our study.

In this study, we used artificial blood vessels (ePTFE vascular grafts) for reconstruction. In our literature review, there were 6 studies [11, 18, 21, 25-27] used both selfanastomosis and prosthesis (allograft), and other 6 studies $[15,17,28-31]$ used self-anastomosis. Usually, the choice of reconstruction method should satisfied following criteria: invaded blood vessels are less than $1 / 3$ of the circumference and with less severe involvement, suture and patch is used; invaded blood vessels are greater than $1 / 3$ of the circumference and less than $5 \mathrm{~cm}$, venous end-to-end anastomosis was used; and invaded blood vessels are longer than $5 \mathrm{~cm}$, artificial blood vessels are commonly used. However, the severity of the invaded PV are based on intraoperative judgments of the operators. In this study, artificial blood vessels were used in order to achieve a radical resection and a negative vessel margin. Likely, ePTFE grafts has been used to secure tumor-free margins for patients in whom tumor-free margins cannot be obtained in liver surgery [33]. Unlike Self-anastomosis (end to end anastomosis, suture, and patch) are more
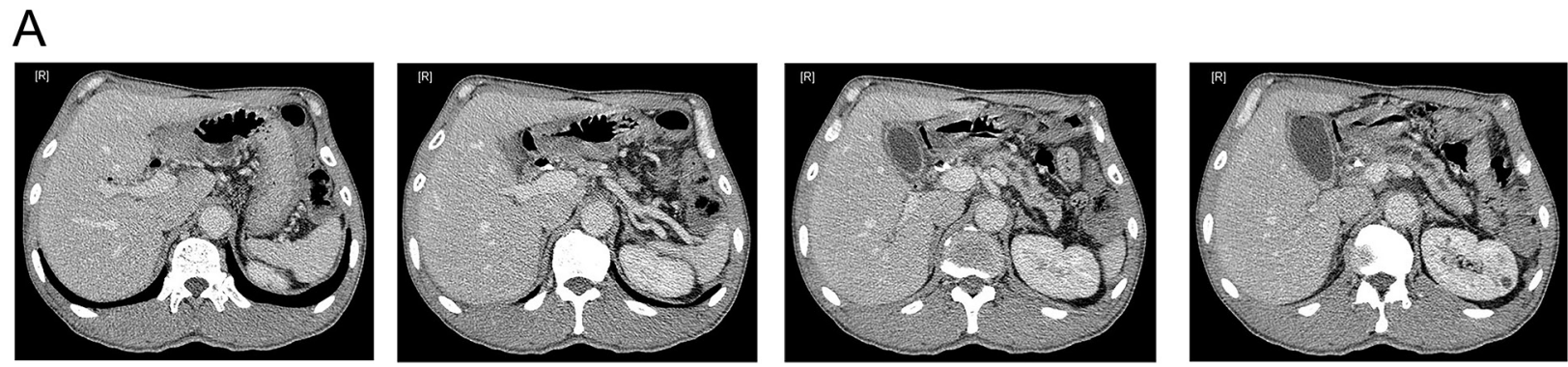

B

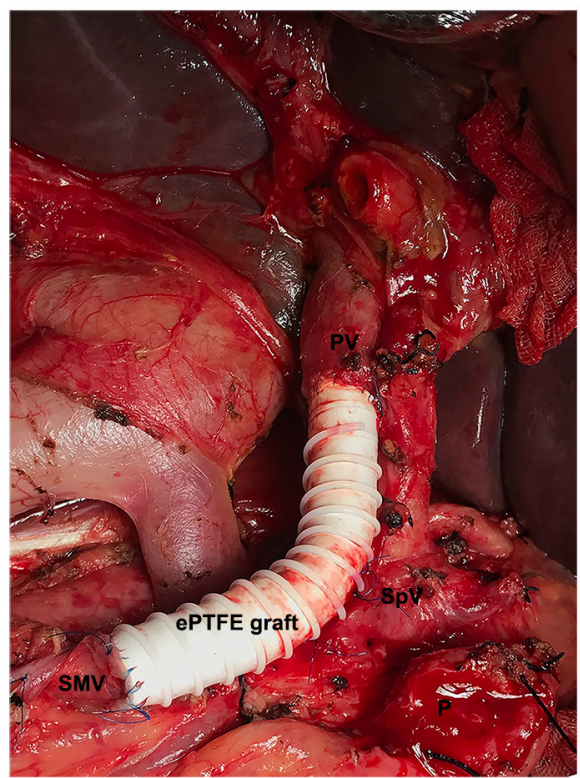

C
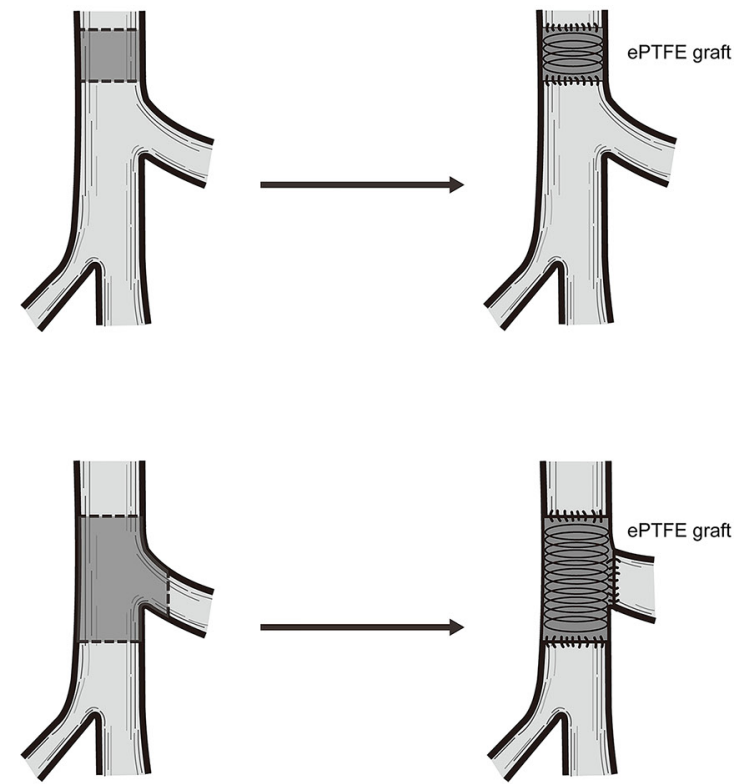

Figure 4: Schema of surgical procedures. (A) CT scan of PDAC patients with PV involvement. (B) Surgical procedure of PD combined with PVR. (C) Sketch map of PD combined with PVR. Abbreviation: CT=Computer tomography, $\mathrm{PD}=$ pancreaticoduodenectomy, $\mathrm{PDAC}=$ pancreatic ductal adenocarcinoma, $\mathrm{PV}=$ Portal vein, $\mathrm{PVR}=$ Portal vein resection. 
likely to raise high tension of the anastomosed PV and may develop portal hypertension. Using ePTFE would reduce this risk. Compliance, lack of thrombogenicity, and resistance to infections as well as the ability to heal, remodel, contract, and secrete normal blood vessel products are theoretical advantages of artificial blood vessels [23, 24]. However, use of an artificial vascular graft has the potential risk of infection and thrombosis. In the use of ePTFE graft in liver surgery, no graft infection were reported [34, 35]. Moreover, ePTFE grafts are considered to have strong resistance to infection compared with other artificial vascular grafts [36]. The potential risk of luminal thrombus of the use of the ePTFE graft in low-flow vessels might be high. Compared with autogenous vein, ePTFE graft showed very high patency rates. The resistance of graft collapse, also resulting in few cases of graft thrombosis development [37]. In our study, patients with PVR were all asked to take aspirin and have ultrasonography examinations. Up till now, no graft infection and thrombosis were reported. However, in our study, the comparison of the benefits between autograft and allograft were not available. If it is possible, we should perform the study with such comparison.

Multivariate analysis showed different therapy choice, BMI and CA 19-9 levels were independent risk factors which influence OS. Patients with PVR suffered significantly longest survivals (mean survival: 22.83 months) may due to the patients with PVR were with resectable primary tumors. In patients with unresectable tumors, surgery would be not appropriate because it would do damage to immune system which may help produce tumor metastasis [38]. However, survivals between patients with SB and patients with chemotherapy were similar (mean survival: SB, 7.26 months; Chemo, 10.64 months, $P=0.064$ ) showed that different therapy would do little to influence the survivals in these patients. Also, patients with BMI less than 18.5 suffered significantly worst survivals. Take a further look at baseline characteristics, BMI was similar among 3 groups while patients in chemotherapy group suffered a significantly lower albumin (ALB) levels. ALB reflects physical nutrition status in some extent [39]. The prognosis would not be good when patients suffered negative nitrogen balance. Patients with BMI less than 18.5 were classified as underfat and suffered worse nutrition status. Thus, it is no wonder that patients with BMI less than 18.5 achieved worse survivals. In our study, higher CA 19-9 levels were associated with worse survival. Likely, Murakami et al. [28] and Shimada et al. [31] found CA 19-9 levels were independent risk factor of survivals. In pancreatic cancer, CA 19-9 levels were strongly correlate with tumor burden which may contribute to prognosis [40]. Thus a higher level of CA 19-9 correlated with a worse survival. Furthermore, fellow survival analysis conducted in patients with PVR also revealed lower BMI and higher CA 19-9 levels were correlated with worse OS which convinced our previous results. Interestingly, the survival analysis conducted in patients with PVR found pathological PV involvement and lymph node metastasis were also prognostic factors. Patients enrolled in our study were all with PV involvement based on initial computed tomography $(\mathrm{CT})$ or magnetic resonance imaging (MRI) evidence. However, the status of PV involvement still needs postoperative pathological evidence. Tumor cells invaded into vascular wall may have a higher risk of developing distal metastasis. Thus a survival difference could be detected between patients with or without pathological PV involvement. Furthermore, patients with lymph node metastasis were classified as tumor stage IIb while patients with simply PV involvement were classified as tumor stage IIa. It was no wonder that patients with a late tumor stage achieved a worse OS.

The biggest limitation in our study is the retrospective study design. We already tried our best to enlarge our sample size. And we are the only study to specifically investigate the appropriate therapy for PDAC patients with PV involvement. At present, the prospective study design referring this issue is not available. Secondly, we are lack of the comparison between patients with autograft and allograft. We will perform the comparison in our future study.

In conclusion, resectable PDAC patients with PV involvement should choose PVR as their first-line treatment.

\section{MATERIALS AND METHODS}

\section{Ethics statement}

This study was approved by the Institutional Review Board of Shanghai Medical College of Fudan University (Shanghai, China), and conducted in accordance with the Declaration of Helsinki and internationally accepted ethical guidelines. The use of human tissue samples and clinical data was approved by the Clinical Research Ethics Committee of Huashan Hospital affiliated to Fudan University. All donors provided written informed consent to donate their samples. All methods were taken in accordance with the approved guidelines of Shanghai Medical College of Fudan University.

\section{Data availability}

All data generated or analyzed during this study are included in this published article.

\section{Patients}

From 2010 to 2015, there were 1382 consecutive PDCA patients admitted to our hospital. To be included in our study, patients had to be (a) aged 18-80 years; (b) without other organ metastasis; (c) clinical diagnosed 
as having PV involvement; (d) Eastern Cooperative Oncology Group score 0-2 and (e) definitively diagnosed with PDCA based on pathologic evidence. Patients were excluded from the study if they (a) had a history of therapy for PDAC; (b) had arterial involvement; (c) had other malignant tumors or extra-pancreatic metastasis.

Within one week before pancreatic surgery, all patients underwent a baseline assessment of serum leukocyte count, serum levels of alanine aminotransferase (ALT), total bilirubin (TBil), ALB; serum levels of carcinoembryonic antigen (CEA), CA125, CA 19-9 and CA 50. All patients were examined by contrast-enhanced CT or MRI, CT angiogram and positron emission tomography-computed tomography (PET-CT) scanning.

\section{Diagnosis of portal vein involvement}

Based on preoperative imaging such as CT or MRI, we determined a high suspicion of PV involvement according to Nakao et al. [41]. Moreover, the possibility of PV involvement was then based on the surgeon's intraoperative visual judgment. Of course, the final evidence of PV involvement were clarified by postoperative pathological diagnosis.

\section{Therapy choice}

We divided PDAC patients into resectable group or unresectable group according to initial examinations of pancreatic tumors by CT or MRI. Patients with resectable PDAC and had the possibility for reconstructions were divided into resectable group. In resectable group, all patients without operation contradictions were undergoing PD and PVR (PVR group). During the operation, we also used intraoperative ultrasound and surgeon's own visual judgments to evaluate the resectability of the primary tumor. Patients with any extra-pancreatic metastasis which were not detected by preoperative PET-CT scanning underwent SB procedure and were excluded from our study. Based on intraoperative surgeon's judgments, patients with PV involvement in resectable group but without possibility of reconstruction (multiple branch involvement) were divided into unresectable group and underwent SB procedure. Patients with unresectable tumors were treated with SB choice if patients were suffered from obstructive symptoms (SB group). For rest patients, we first used endoscopic ultrasound guided fine needle aspiration (FNA) biopsy for the confirm of the diagnosis of PDAC, followed by chemotherapy (chemotherapy group) (Flow was shown as Figure 3).

\section{Surgical procedures}

For patients with resectable tumors, PD with PVR was performed. PD was performed a classic Whipple procedures. The Whipple's procedure commonly performed was PD with end-to-side pancreaticojejunostomy, end-to-side hepaticojejunostomy, and anterior-colic gastrojejunostomy. Two drains were placed at the end of the procedure in the foramen of Winslow and along with upper and below edge of the pancreaticojejunostomy. PVR were carried out en-bloc as primary closure of the vein, and reconstructed with ePTFE vascular grafts (Bard Peipheral Vascular, Inc).

For patients with unresectable tumors, SB (hepaticojejunostomy with or without gastrojejunostomy) was performed. Intraoperative FNA was also conducted to provide the pathological evidence of the diagnosis of PDAC (Schema of surgical procedures were shown as Figure 4).

\section{Chemotherapy}

In this study, the chemotherapy used in chemo group or used as the adjuvant therapy after surgery (both PD and SB) was intra-arterial infusion chemotherapy (IRIC) [42]. We placed 5-Fr Rosch hepatic catheters and used Seldinger's technique via the femoral artery. We reconfirmed the position by digital subtraction angiography (DSA) with the tip into the hepatic artery or the superior mesenteric artery (SMA). The mixture of 5-fluorouracil $\left(600 \mathrm{mg} / \mathrm{m}^{2}\right)$, cisplatin/oxaliplatin $(30 \mathrm{mg} /$ $\left.\mathrm{m}^{2}\right)$ and gemcitabine $\left(1000 \mathrm{mg} / \mathrm{m}^{2}\right)$ was then injected into SMA. Any patients received chemotherapy were given one cycle every 4 weeks for 6 cycles.

\section{Postoperative management}

Patients were required to reexamine every 4 weeks. The same serum tests as baseline were tested. An increase of serum CA 19-9 levels with the abnormal mass of the residue pancreas discovered by $\mathrm{CT}$ or MRI was defined as recurrence. In PVR and SB group, patients were given IRIC one cycle every 4 weeks for 6 cycles.

For patients underwent PD with PVR, aspirin 50$100 \mathrm{mg}$ per day were given. And B-ultrasonic test was required at every reexamination to determine the condition of the interposition graft.

\section{Outcomes}

At baseline, body mass index (BMI), leucocytes, ALB, TBil, ALT, CEA, CA 125, CA 19-9, CA 50 were compared among 3 groups. Tumor diameters, operation time, blood loss were recorded intra-operatively and compared between 2 surgical groups. Primary outcomes were OS, and secondary outcomes were surgical complications.

Pancreatic fistula (PF), delayed gastric emptying (DGE) and intra-abdominal hemorrhage were defined according to the International Study Group of Pancreatic Surgery $[43,44]$. Intra-abdominal infection was defined according to the Centers for Disease Control and Prevention [45]. Mortality was defined as any death that occurred in the 30 days after surgery or during the hospital stay. 


\section{Statistical analysis}

The soft SPSS 21.0 (IBM, Chicago, USA) was used for statistical analysis, and $\mathrm{P}<0.05$ was defined as the threshold of statistical significance. Normally distributed data was expressed as mean \pm standard deviation (SD), while asymmetrically distributed data was expressed as median (range). Differences in outcomes among PVR group, SB group and chemo group were assessed for significance using ANOVA tests. Kaplan-Meier method was used to calculate survival curves. Multivariate survival analysis was performed by Cox proportional hazards model.

\section{Literature review}

We also conducted a literature review, systematically reviewed Pubmed, web of science, and Cochrane Library using following key words: "pancreatic cancer" OR "pancreatic ductal adenocarcinoma"; "portal vein"; "resection" OR "surgery" to evaluate the benefit of radical pancreatectomy with PVR. Studies enrolled in this review should (a) have at least 2 arms (PVR vs. not-PVR); (b) carefully described the tumor stage of enrolled patients; (c) reported survival data.

\section{Abbreviations}

$\mathrm{ALB}=$ albumin, $\mathrm{ALT}=$ alanine aminotransferase, $\mathrm{BMI}=$ body mass index, $\mathrm{CA}=$ carbohydrateantigen, $\mathrm{CEA}$ $=$ carcinoembryonic antigen, $\mathrm{CI}=$ confidence interval, $\mathrm{CT}$ $=$ computed tomography, $\mathrm{FNA}=$ fine needle aspiration, $\mathrm{HR}=$ hazard ratio, IRIC = intra-arterial infusion chemotherapy, MRI = magnetic resonance imaging, $\mathrm{PD}=$ pancreaticoduodenectomy, $\mathrm{PDAC}=$ pancreatic ductal adenocarcinoma, PET-CT $=$ positron emission tomography-computed tomography, $\mathrm{PV}=$ portal vein, $\mathrm{PVR}=$ portal vein resection, $\mathrm{SB}=$ surgical bypass, $\mathrm{TBil}$ $=$ total bilirubin.

\section{Author contributions}

Conception and design: Zhi-Bo Xie, Yi-Fan Zhang and De-Liang Fu; administrative support: Zhi-Bo Xie, JiChun Gu, Yi-Fan Zhang and De-Liang Fu; provision of study materials or patients: Lie Yao, Chen Jin, Yong-Jian Jiang, Ji Li, Feng Yang, Cai-Feng Zou and De-Liang Fu; collection and assembly of data: Ji-Chun Gu and Cai-Feng Zou; data analysis and interpretation: Zhi-Bo Xie, Ji-Chun Gu, Yi-Fan Zhang and De-Liang Fu; manuscript writing: all authors; final approval of manuscript: All authors.

\section{ACKNOWLEDGMENTS}

We thank Pro. Shun-Xing Zhang for language editing.

\section{CONFLICTS OF INTEREST}

The authors disclose no conflicts of interest.

\section{GRANT SUPPORT}

This work was supported by grants from the National Natural Science Foundation of China (No. 81472221) and Clinical key projects of the National Health and Family Planning (Oncology 2013-2015).

\section{REFERENCES}

1. Siegel R, Ma J, Zou Z, Jemal A. Cancer statistics, 2014. CA Cancer J Clin. 2014; 64: 9-29. https://doi.org/10.3322/ caac. 21208.

2. He J, Chen W. Chinese Cancer Registry Annual Report 2012. Beijing. Press of Military Medical Sciences. 2012: 68-71.

3. Ryan DP, Hong TS, Bardeesy N. Pancreatic adenocarcinoma. N Engl J Med. 2014; 371: 2140-1. https:// doi.org/10.1056/NEJMc1412266.

4. Zell JA, Rhee JM, Ziogas A, Lipkin SM, Anton-Culver H. Race, socioeconomic status, treatment, and survival time among pancreatic cancer cases in California. Cancer Epidemiol Biomarkers Prev. 2007; 16: 546-52. https://doi. org/10.1158/1055-9965.EPI-06-0893.

5. Lau MK, Davila JA, Shaib YH. Incidence and survival of pancreatic head and body and tail cancers: a populationbased study in the United States. Pancreas. 2010; 39: 45862. https://doi.org/10.1097/MPA.0b013e3181bd6489.

6. Quaresma M, Coleman MP, Rachet B. 40-year trends in an index of survival for all cancers combined and survival adjusted for age and sex for each cancer in England and Wales, 1971-2011: a population-based study. Lancet. 2015; 385: 120618. https://doi.org/10.1016/S0140-6736(14)61396-9.

7. Long J, Luo GP, Xiao ZW, Liu ZQ, Guo M, Liu L, Liu C, Xu J, Gao YT, Zheng Y, Wu C, Ni QX, Li M, et al. Cancer statistics: current diagnosis and treatment of pancreatic cancer in Shanghai, China. Cancer Lett. 2014; 346: 273-7. https://doi.org/10.1016/j.canlet.2014.01.004.

8. Sener SF, Fremgen A, Menck HR, Winchester DP. Pancreatic cancer: a report of treatment and survival trends for 100,313 patients diagnosed from 1985-1995, using the National Cancer Database. J Am Coll Surg. 1999; 189: 1-7.

9. Hirano S, Kondo S, Hara T, Ambo Y, Tanaka E, Shichinohe T, Suzuki O, Hazama K. Distal pancreatectomy with en bloc celiac axis resection for locally advanced pancreatic body cancer: long-term results. Ann Surg. 2007; 246: 46-51. https://doi.org/10.1097/01.sla.0000258608.52615.5a.

10. Tanaka E, Hirano S, Tsuchikawa T, Kato K, Matsumoto J, Shichinohe T. Important technical remarks on distal pancreatectomy with en-bloc celiac axis resection for locally advanced pancreatic body cancer (with video). J 
Hepatobiliary Pancreat Sci. 2012; 19: 141-7. https://doi. org/10.1007/s00534-011-0473-7.

11. Gong Y, Zhang L, He T, Ding J, Zhang H, Chen G, Zhang D, Wu Z, Chen Q, Fan H, Wang Q, Bie P, Wang H. Pancreaticoduodenectomy combined with vascular resection and reconstruction for patients with locally advanced pancreatic cancer: a multicenter, retrospective analysis. PLoS One. 2013; 8: e70340. https://doi.org/10.1371/journal. pone.0070340.

12. Castleberry AW, White RR, De La Fuente SG, Clary BM, Blazer DG 3rd, McCann RL, Pappas TN, Tyler DS, Scarborough JE. The impact of vascular resection on early postoperative outcomes after pancreaticoduodenectomy: an analysis of the American College of Surgeons National Surgical Quality Improvement Program database. Ann Surg Oncol. 2012; 19: 4068-77. https://doi.org/10.1245/ s10434-012-2585-y.

13. Heinemann V, Haas M, Boeck S. Neoadjuvant treatment of borderline resectable and non-resectable pancreatic cancer. Ann Oncol. 2013; 24: 2484-92. https://doi.org/10.1093/ annonc/mdt239.

14. Giovinazzo F, Turri G, Katz MH, Heaton N, Ahmed I. Meta-analysis of benefits of portal-superior mesenteric vein resection in pancreatic resection for ductal adenocarcinoma. Br J Surg. 2016; 103: 179-91. https://doi.org/10.1002/ bjs.9969.

15. Hwang JW, Kim SC, Song KB, Yoon JH, Nam JS, Lee JH, Park KM, Lee YJ. Significance of radiologic location and extent of portal venous involvement on prognosis after resection for pancreatic adenocarcinoma. Pancreas. 2015; 44: 665-71. https://doi.org/10.1097/MPA.0000000000000309.

16. Mierke F, Hempel S, Distler M, Aust DE, Saeger HD, Weitz J, Welsch T. Impact of portal vein involvement from pancreatic cancer on metastatic pattern after surgical resection. Ann Surg Oncol. 2016; 23: 730-6. https://doi. org/10.1245/s10434-016-5515-6.

17. Ouaissi M, Hubert C, Verhelst R, Astarci P, Sempoux C, Jouret-Mourin A, Loundou A, Gigot JF, Multidisciplary HPBGoCoC. Vascular reconstruction during pancreatoduodenectomy for ductal adenocarcinoma of the pancreas improves resectability but does not achieve cure. World J Surg. 2010; 34: 2648-61. https://doi.org/10.1007/ s00268-010-0699-6.

18. Bachellier P, Nakano H, Oussoultzoglou PD, Weber JC, Boudjema K, Wolf PD, Jaeck D. Is pancreaticoduodenectomy with mesentericoportal venous resection safe and worthwhile? Am J Surg. 2001; 182: 120-9.

19. Martin RC 2nd, Scoggins CR, Egnatashvili V, Staley CA, McMasters KM, Kooby DA. Arterial and venous resection for pancreatic adenocarcinoma: operative and longterm outcomes. Arch Surg. 2009; 144: 154-9. https://doi. org/10.1001/archsurg.2008.547.

20. Mierke F, Hempel S, Distler M, Aust DE, Saeger HD, Weitz J, Welsch T. Impact of Portal Vein Involvement from Pancreatic Cancer on Metastatic Pattern After Surgical
Resection. Ann Surg Oncol. 2016. https://doi.org/10.1245/ s10434-016-5515-6.

21. Flis V, Potrc S, Kobilica N, Ivanecz A. Pancreaticoduodenectomy for ductal adenocarcinoma of the pancreatic head with venous resection. Radiol Oncol. 2016; 50: 321-8. https://doi.org/10.1515/raon-2015-0017.

22. Tseng JF, Raut CP, Lee JE, Pisters PW, Vauthey JN, Abdalla EK, Gomez HF, Sun CC, Crane CH, Wolff RA, Evans DB. Pancreaticoduodenectomy with vascular resection: margin status and survival duration. J Gastrointest Surg. 2004; 8: 935-49; discussion 49-50. https://doi.org/10.1016/j. gassur.2004.09.046.

23. Kakisis JD, Liapis CD, Breuer C, Sumpio BE. Artificial blood vessel: the Holy Grail of peripheral vascular surgery. J Vasc Surg. 2005; 41: 349-54. https://doi.org/10.1016/j. jvs.2004.12.026.

24. Matsuda T. Recent progress of vascular graft engineering in Japan. Artif Organs. 2004; 28: 64-71.

25. Chakravarty KD, Hsu JT, Liu KH, Yeh CN, Yeh TS, Hwang TL, Jan YY, Chen MF. Prognosis and feasibility of en-bloc vascular resection in stage II pancreatic adenocarcinoma. World J Gastroenterol. 2010; 16: 997-1002.

26. Cheung TT, Poon RT, Chok KS, Chan AC, Tsang SH, Dai WC, Chan SC, Fan ST, Lo CM. Pancreaticoduodenectomy with vascular reconstruction for adenocarcinoma of the pancreas with borderline resectability. World J Gastroenterol. 2014; 20 : 17448-55. https://doi.org/10.3748/wjg.v20.i46.17448.

27. Hartel M, Niedergethmann M, Farag-Soliman M, Sturm JW, Richter A, Trede M, Post S. Benefit of venous resection for ductal adenocarcinoma of the pancreatic head. Eur $\mathrm{J}$ Surg. 2002; 168: 707-12.

28. Murakami Y, Satoi S, Motoi F, Sho M, Kawai M, Matsumoto I, Honda G, Multicentre Study Group of Pancreatobiliary S. Portal or superior mesenteric vein resection in pancreatoduodenectomy for pancreatic head carcinoma. Br J Surg. 2015; 102: 837-46. https://doi. org/10.1002/bjs.9799.

29. Murakami Y, Uemura K, Sudo T, Hashimoto Y, Nakashima A, Kondo N, Nakagawa N, Sueda T. Benefit of portal or superior mesenteric vein resection with adjuvant chemotherapy for patients with pancreatic head carcinoma. J Surg Oncol. 2013; 107: 414-21. https://doi.org/10.1002/ jso.23229.

30. Ravikumar R, Sabin C, Abu Hilal M, Bramhall S, White S, Wigmore S, Imber CJ, Fusai G, Group UKVRiPCS. Portal vein resection in borderline resectable pancreatic cancer: a United Kingdom multicenter study. J Am Coll Surg. 2014; 218: 401-11. https://doi.org/10.1016/j. jamcollsurg.2013.11.017.

31. Shimada K, Sano T, Sakamoto Y, Kosuge T. Clinical implications of combined portal vein resection as a palliative procedure in patients undergoing pancreaticoduodenectomy for pancreatic head carcinoma. Ann Surg Oncol. 2006; 13: 1569-78. https://doi.org/10.1245/s10434-006-9143-4. 
32. Louvet C, Philip PA. Accomplishments in 2007 in the treatment of metastatic pancreatic cancer. Gastrointest Cancer Res. 2008; 2: S37-41.

33. Hemming AW, Mekeel KL, Zendejas I, Kim RD, Sicklick JK, Reed AI. Resection of the liver and inferior vena cava for hepatic malignancy. J Am Coll Surg. 2013; 217: 115-24; discussion 24-5. https://doi.org/10.1016/j. jamcollsurg.2012.12.003.

34. Azoulay D, Andreani P, Maggi U, Salloum C, Perdigao F, Sebagh M, Lemoine A, Adam R, Castaing D. Combined liver resection and reconstruction of the supra-renal vena cava: the Paul Brousse experience. Ann Surg. 2006; 244: 80-8. https://doi.org/10.1097/01.sla.0000218092.83675.bc.

35. Arii S, Teramoto K, Kawamura T, Takamatsu S, Sato E, Nakamura N, Iwai T, Mori A, Tanaka J, Imamura M. Significance of hepatic resection combined with inferior vena cava resection and its reconstruction with expanded polytetrafluoroethylene for treatment of liver tumors. J Am Coll Surg. 2003; 196: 243-9. https://doi.org/10.1016/ S1072-7515(02)01616-2.

36. Yamamoto Y. Ante-situm hepatic resection for tumors involving the confluence of hepatic veins and IVC. J Hepatobiliary Pancreat Sci. 2013; 20: 313-23. https://doi. org/10.1007/s00534-012-0525-7.

37. Nuzzo G, Giordano M, Giuliante F, Lopez-Ben S, Albiol M, Figueras J. Complex liver resection for hepatic tumours involving the inferior vena cava. Eur J Surg Oncol. 2011; 37: 921-7. https://doi.org/10.1016/j.ejso.2011.08.132.

38. Xie ZB, Wang XB, Fu DL, Zhong JH, Yang XW, Li LQ. Postoperative hepatitis $\mathrm{B}$ virus reactivation in hepatitis $\mathrm{B}$ virus-related hepatocellular carcinoma patients with hepatitis B virus DNA levels $<500$ copies/mL. Onco Targets Ther. 2016; 9: 4593-603. https://doi.org/10.2147/OTT.S104300.
39. Ding D, Feng Y, Song B, Gao S, Zhao J. Effects of preoperative and postoperative enteral nutrition on postoperative nutritional status and immune function of gastric cancer patients. Turk J Gastroenterol. 2015; 26: 1815. https://doi.org/10.5152/tjg.2015.3993.

40. Schlieman MG, Ho HS, Bold RJ. Utility of tumor markers in determining resectability of pancreatic cancer. Arch Surg. 2003; 138: 951-5; discussion 5-6. https://doi.org/10.1001/ archsurg.138.9.951.

41. Nakao A, Harada A, Nonami T, Kaneko T, Inoue S, Takagi H. Clinical significance of portal invasion by pancreatic head carcinoma. Surgery. 1995; 117: 50-5.

42. Jin C, Yao L, Long J, Fu DL, Yu XJ, Xu J, Yang F, Ni QX. Effect of multiple-phase regional intra-arterial infusion chemotherapy on patients with resectable pancreatic head adenocarcinoma. Chin Med J (Engl). 2009; 122: 284-90.

43. Bassi C, Dervenis C, Butturini G, Fingerhut A, Yeo C, Izbicki J, Neoptolemos J, Sarr M, Traverso W, Buchler M, International Study Group on Pancreatic Fistula D. Postoperative pancreatic fistula: an international study group (ISGPF) definition. Surgery. 2005; 138: 8-13. https:// doi.org/10.1016/j.surg.2005.05.001.

44. van Berge Henegouwen MI, van Gulik TM, DeWit LT, Allema JH, Rauws EA, Obertop H, Gouma DJ. Delayed gastric emptying after standard pancreaticoduodenectomy versus pylorus-preserving pancreaticoduodenectomy: an analysis of 200 consecutive patients. J Am Coll Surg. 1997; 185: 373-9.

45. Horan TC, Gaynes RP, Martone WJ, Jarvis WR, Emori TG. CDC definitions of nosocomial surgical site infections, 1992: a modification of CDC definitions of surgical wound infections. Infect Control Hosp Epidemiol. 1992; 13: 606-8. 